\title{
Effects on Differentiation of Embryonic Ventral Midbrain Progenitors by Lmx1a, Msx1, Ngn2, and Pitx3
}

\author{
Laurent Roybon, ${ }^{\star}$ Tord Hjalt, ${ }^{\star}$ Nicolaj S. Christophersen, Jia-Yi Li, and Patrik Brundin \\ Neuronal Survival Unit, Department of Experimental Medical Science, 22184 Lund, Sweden
}

\begin{abstract}
Neurons derived from neural stem cells could potentially be used for cell therapy in neurodegenerative disorders, such as Parkinson's disease. To achieve controlled differentiation of neural stem cells, we expressed transcription factors involved in the development of midbrain dopaminergic neurons in rat and human neural progenitors. Using retroviral-mediated transgene delivery, we overexpressed Lmx1a (LIM homeobox transcription factor 1, alpha), Msx1 (msh homeobox homolog 1), Ngn2 (neurogenin 2), or Pitx3 (paired-like homeodomain transcription factor 3) in neurospheres derived from embryonic day 14.5 rat ventral mesencephalic progenitors. We also expressed either Lmx1a or Msx1 in the human embryonic midbrain-derived progenitor cell line NGC-407. Rat cells transduced with Ngn2 exited the cell cycle and expressed the neuronal marker microtubule-associated protein 2 and catecholamine-neuron protein vesicular monoamine transporter 2. Interestingly, Pitx3 downregulated the expression of SOX2 (SRY-box containing gene 2) and Nestin, altered cell morphology, but never induced neuronal or glial differentiation. Ngn2 exhibited a strong neuron-inducing effect. In contrast, few Lmxla-transduced cells matured into neurons, and Msxl overexpression promoted oligodendrogenesis rather than neuronal differentiation. Importantly, none of these four genes, alone or in combination, enhanced differentiation of rat neural stem cells into dopaminergic neurons. Notably, the overexpression of Lmxla, but not Msxl, in human neural progenitors increased the yield of tyrosine hydroxylase-immunoreactive cells by threefold. Together, we demonstrate that induced overexpression of transcription factor genes has profound and specific effects on the differentiation of rat and human midbrain progenitors, although few dopamine neurons are generated.
\end{abstract}

Key words: ventral mesencephalic progenitors; cell line; neuronal differentiation; dopaminergic neurons; Ngn2; Pitx3; Msx1; Lmx1a; retrovirus

\section{Introduction}

The concept that cell transplantation can be used to repair the brain in neurological disease has received great attention. For example, transplants of dopaminergic neurons derived from aborted human embryos can be beneficial in Parkinson's disease (PD) (Olanow et al., 1996; Lindvall and Hagell, 2000; Björklund et al., 2003). The main drawbacks are relative shortage of suitable embryonic donor tissue and ethical issues related to the need for a constant supply of tissue from aborted embryos. Some of these problems would be solved if it were possible to derive the transplant neurons from neural stem/progenitor cells. Rodent and

\footnotetext{
Received Dec. 23, 2006; revised Feb. 21, 2008; accepted Feb. 25, 2008.

This work was supported by NeuroFortis, Thorsten och Elsa Segerfalks Stiftelse, Swedish Research Council, the Swedish Parkinson Foundation, Torsten och Ragnar Söderbergs stiftelser, Konung Gustaf V:s och Drottning Victorias Stiftelse, and the Swedish Brain Foundation. L.R. was supported by the European Commission through the Framework Program 6 project STEMS (LHSB-CT-2006-037328), and N.S.C. is sponsored by Lundbeckfonden (Grant R7A686). We thank Profs. J. Ericson and T. Perlmann (Karolinska Institute, Stockholm, Sweden), Prof. J. Song (Cell and Gene Therapy Research Institute, Pochon, Korea), and Prof. J. Frisén (Karolinska Institute, Stockholm, Sweden) for providing us with certain CDNA and some of the retrovirus constructs. We thank Profs. M. P. Smidt, M. German, and R. G. Lindahl for their generous gift of antibodies, Birgit Haraldsson, Britt Lindberg, and Marianne Rissler for excellent technical assistance, and Birgitta Larsson for her help in grant administration.

${ }^{*}$ L.R. and T.H. contributed equally to this work.

Correspondence should be addressed to Laurent Roybon, Neuronal Survival Unit, Division for Neuroscience, Department of Experimental Medical Science, Wallenberg Neuroscience Center, BMC A10, 22184 Lund, Sweden. E-mail: laurent.roybon@med.lu.se.

DOI:10.1523/JNEUROSCI.0311-08.2008

Copyright $\odot 2008$ Society for Neuroscience $\quad$ 0270-6474/08/283644-13\$15.00/0
}

human embryo-derived neurospheres contain multipotent stem/ progenitor cells that can proliferate and differentiate into all neural lineages. Rodent neurospheres are excellent tools for, as an example, experimental studies in the areas of stem cell biology and brain repair (Reynolds and Weiss, 1996; Svendsen et al., 1999; Kim et al., 2006). Human neurospheres, conversely, could potentially be used in toxicity studies, screening novel drugs, and as an interesting potential source of cells for neural grafting in PD patients. Unfortunately, when grown as neurospheres, even the most dedicated culture protocols only generate a small number $(<5 \%)$ of dopaminergic neurons, which is the required cell type for grafting in PD (Studer et al., 1998; Sanchez-Pernaute et al., 2001; Kim et al., 2003; Roybon et al., 2004; Jensen and Parmar, 2006).

Several protocols aimed at generating midbrain dopaminergic neurons from different types of cells have been tested. They include coculture systems (Kawasaki et al., 2000, 2002; Barberi et al., 2003; Perrier et al., 2004), gene delivery strategies (Raymon et al., 1997; Wagner et al., 1999; Kordower et al., 2000; Andersson et al., 2007; Kim et al., 2007), and addition of exogenous growth factors to the cultures (Ye et al., 1998; Castelo-Branco et al., 2003; Schulte et al., 2005; Martinat et al., 2006; Bryja et al., 2007). The recent increase in knowledge of the transcriptional control of midbrain dopaminergic neurons during normal development may help to create methods that generate higher numbers of 
dopaminergic neurons from stem cells. Development of midbrain dopaminergic neurons is complex and involves the activation of partially identified transcriptional cascades (Perlmann and Wallen-Mackenzie, 2004; Simon et al., 2004). Mutant mouse models and gene targeting studies have elucidated the role of many of these transcription factors (Smits et al., 2003; Zhao et al., 2004; Sgado et al., 2006). For example, the proneural basic helixloop-helix transcription factor Ngn2 (neurogenin 2) is required for the proneural specification and pan-neuronal character of ventral midbrain dopaminergic neurons (Andersson et al., 2006a; Kele et al., 2006). In contrast, the homeobox gene Pitx3 (paired-like homeodomain transcription factor 3 ) seems to play a role in the survival and maintenance of dopaminergic neurons rather than as an upstream signal for neuronal specification (Smidt et al., 2004). A recent study identified two genes, Lmxla (LIM homeobox transcription factor 1, alpha) and Msx1 (msh homeobox homolog 1), as major upstream regulators of the dopaminergic neuronal subtype specification. Expression of Lmxla driven by the neural-specific nestin enhancer coupled to a minimal thymidine kinase promoter (Lothian et al., 1999) induced the maturation of mouse embryonic stem cells (ESCs) into ventral midbrain dopaminergic neurons when sonic hedgehog $(\mathrm{SHH})$ and fibroblast growth factor 8 (FGF8) were present in the medium (Andersson et al., 2006b).

Using single or double gene transduction, we have examined the effects of the constitutive expression of each of the genes Lmx1a, Msx1, Pitx3, and Ngn2 on embryonic day 14.5 (E14.5) rat and 7 -week-old human ventral mesencephalic neural precursors. The genes all had specific effects on the neural differentiation of the precursors into different lineages. However, the single action or dual combinations of these genes, in the presence or absence of growth factors, were not sufficient to induce midbrain precursors to differentiate into dopaminergic neurons with high yields.

\section{Materials and Methods}

Retroviral vectors construction, production, and titration. We generated retroviral vectors pCMMP-Lmxla-IRES2eGFP-WPRE, pCMMPMsx1-IRES2eGFP-WPRE, and pCMMP-Pitx3-IRES2eGFP-WPRE by PCR amplifying the cDNA using high-fidelity polymerase Advantage 2 (Clontech, Mountain View, CA) of mouse Lmxla, mouse Msx1 (Andersson et al., 2006b), and rat Pitx3 (Prof. J. Song, Cell and Gene Therapy Research Institute, Pochon, Korea). [There were some anomalies in the original mLmxla clone we observed after sequencing and which consisted of a changed second codon (Leu-Val) and 16 additional amino acids appended to the end of the reading frame (TSNSPITSLFAAPGTR) and a different stop codon (TGA-TAA), which we corrected by PCR using primers congruent to the mLmxla sequence in GenBank (accession number NM_033652.2).] We cloned the genes into the restriction sites PmeI ( $\left.5^{\prime}\right)$ and XhoI ( $\left.3^{\prime}\right)$ of the pCMMP-IRES2eGFP-WPRE vector (Hofstetter et al., 2005). We generated the retroviral vector pCMMPLmx1a-IRES2DsRed2-WPRE by substituting the IRES2eGFP sequence for an IRES2DsRed2 sequence, using the restriction sites XhoI and NotI. The constructs were confirmed using restriction digestion and DNA sequencing. We produced all viruses according to a protocol described previously, using the producer cell line 293VSVG (Ory et al., 1996). We resuspended the concentrated viruses into $0.5 \mathrm{ml}$ of DMEM (Sigma, St. Louis, MO). The titers varied from $0.7 \times 10^{-9}$ to $1.8 \times 10^{-9} \mathrm{TU} / \mathrm{ml}$.

Rat neurosphere transduction and differentiation. We generated and differentiated neurospheres according to a protocol described previously (Roybon et al., 2005). In brief, we dissected ventral mesencephalic tissue from rat embryos at E14.5. We trypsinized and dissociated the tissue and seeded single-cell suspensions. We passaged the neurospheres weekly, by mechanical dissociation. After $7 \mathrm{~d}$ of expansion in vitro, we seeded E14.5 ventral mesencephalic and cortical neurospheres (passage two is P2) onto poly-L-lysine ( $4 \mu \mathrm{g} / \mathrm{ml}$; Sigma)/laminin ( $5 \mu \mathrm{g} / \mathrm{ml}$; Sigma) (PLL/L)- coated $13 \mathrm{~mm}$ glass coverslips in 24 -well plates. Each well contained an equal starting population of 200,000 cells $/ \mathrm{ml}$, corresponding to $15-25$ neurospheres. We transduced the wells independently with one of the retroviruses or a combination of two retroviruses, at a multiplicity of infection (MOI) of 1 , in proliferation medium supplemented with protamine-sulfate ( $4 \mathrm{mg} / \mathrm{ml}$; Sigma). We replaced the medium with normal basic differentiation medium $3 \mathrm{~d}$ after transduction and subsequently changed it every third day. Cells started to express green fluorescent protein (GFP) and differentiate within 12-24 h (see Fig. 4A1-A4). We fixed the cultures 4,8 , and $12 \mathrm{~d}$ after the induction of differentiation. For semiquantitative reverse transcription (RT)-PCR, we seeded E14.5 rat ventral midbrain neurospheres (P2) in PLL/L-coated flasks containing proliferation medium and transduced them with an MOI of 1 . To study the effect of SHH on Lmxla-, Msx1-, and double-transduced cultures, we supplemented the medium already containing $100 \mathrm{ng} / \mathrm{ml} \mathrm{FGF8}$ with one of two concentrations of SHH ( 1.7 or $15 \mathrm{~nm}$ ) from day 0 to day 16. We changed the medium every third day and fixed the cultures at days 8,12 , and 16 for immunocytochemical stainings for tyrosine hydroxylase (TH) and other dopaminergic markers.

$R T-P C R$. We prepared RNA from freshly trypsinized cells at days 4, 8, and 12 of differentiation, using Trizol (Invitrogen, Carlsbad, CA) and RNeasy CleanUp (Qiagen, Valencia, CA), according to the instructions of the manufacturers. We performed reverse transcription using Superscript II (Invitrogen), with both random hexamers and oligo-dT reverse primers (Promega, Madison, WI). We amplified cDNA using Advantage2 polymerase (Invitrogen) and a PerkinElmer Life and Analytical Sciences (Waltham, MA) 9700 machine. The cycling conditions were as follows: 10 cycles of $94^{\circ} \mathrm{C}$ for $30 \mathrm{~s}, 68^{\circ} \mathrm{C}$ for $90 \mathrm{~s}$, followed by 25 cycles of $94^{\circ} \mathrm{C}$ for $30 \mathrm{~s}, 60^{\circ} \mathrm{C}$ for $1 \mathrm{~min}, 68^{\circ} \mathrm{C}$ for $1 \mathrm{~min}$, and finally $68^{\circ} \mathrm{C}$ for $2 \mathrm{~min}$, soak at $8^{\circ} \mathrm{C}$. We designed the primers to straddle intron-exon boundaries and span introns (supplemental Table 1, available at www.jneurosci.org as supplemental material), with the exception of the enhanced GFP (eGFP) primers, which were designed for an unspliced eGFP cDNA construct. If multiple transcriptional isoforms were known, such as for Nurr1 (nuclear receptor-related 1), we designed primers to amplify all known isoforms.

Human embryonic NGC-407 cell line generation, proliferation, transduction, and differentiation. The NGC-407 cell line was derived at NsGene (Ballerup, Denmark). Cells had been isolated from the ventral midbrain (VM) of a 7-week-old human embryo and immortalized using a retroviral vector containing the v-myc oncogene (Khan et al., 2007). Briefly, human midbrain cells in primary culture were prepared from a 7-week-old human fetal brain (in accordance with Lund University ethical guidelines). Immediately after dissection of the ventral midbrain, the tissue was cut in a drop of cell dissociation solution (Sigma) made of DMEM/F-12 (Invitrogen), N2 supplement (Invitrogen), supplemented with $0.5 \%$ human serum albumin (Sigma), $0.6 \%$ glucose (Sigma), $5 \mathrm{~mm}$ HEPES (Invitrogen), B27 supplement (Invitrogen), $40 \mathrm{ng} / \mathrm{ml}$ basic FGF (bFGF) (R\&D Systems, Minneapolis, MN), and $20 \mathrm{ng} / \mathrm{ml}$ epidermal growth factor (EGF) (R\&D Systems). The cut tissue was centrifuged at $1000 \mathrm{rpm}$ for $5 \mathrm{~min}$ and resuspended in fresh culture medium. Four days after seeding, the cell cultures were transduced at an MOI of 1 with a retroviral vector construct consisting of the gag-v-myc fragment of v-myc (GenBank accession number AF033809) cloned as an EcoRI/DraI fragment between EcoRI and HpaI sites of pLXSN (Clontech) (GenBank accession number M28248). A gene conferring neomycin resistance present in the vector allowed selection of transduced cells by adding geneticin at a concentration of $800 \mu \mathrm{g} / \mathrm{ml}$. After selection, cultures were grown as an adherent monolayer in N2 medium supplemented with EGF and bFGF that was renewed every $2-3 \mathrm{~d}$. We transduced proliferating NGC-407 cells overnight with Lmxla, Msxl, and empty (control) retrovirus at an MOI of 1 . After an additional $48 \mathrm{~h}$, we removed the growth factors bFGF and EGF, which resulted in differentiation of the cells. To study the effect of SHH and FGF8 on Lmxla- and Msx1-transduced cultures, we supplemented the medium with 1-10 nм SHH-N (R\&D Systems) and $100 \mathrm{ng} / \mathrm{ml} \mathrm{FGF8b} \mathrm{(R \& D} \mathrm{Systems).} \mathrm{Half} \mathrm{of} \mathrm{the} \mathrm{medium} \mathrm{was}$ replaced every second day. We fixed the cultures $8 \mathrm{~d}$ after transduction.

Immunocytochemistry. We fixed both rat and human cultures in $4 \%$ paraformaldehyde in $0.1 \mathrm{M}$ PBS for $30 \mathrm{~min}$ and washed with PBS three 

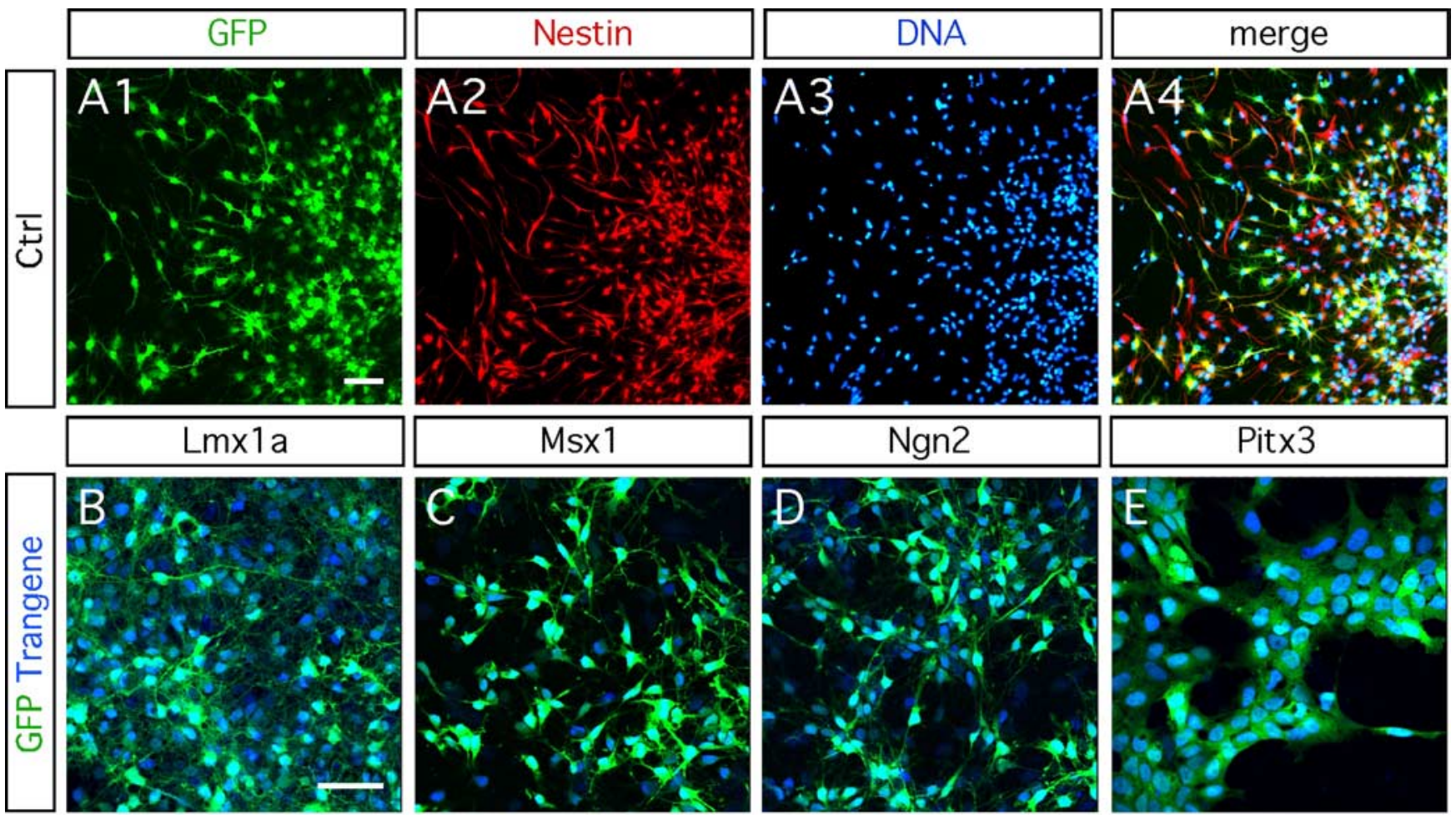

Figure 1. Neural progenitors isolated from E14.5 rat midbrain have a high transduction capacity. A1-A4, Eighty percent of the ventral mesencephalic progenitors are transduced by the retrovirus and express the immature neural marker Nestin. $\boldsymbol{B}-\boldsymbol{E}$, Ventral mesencephalic progenitors transduced with Lmx1a, Msx1, Ngn2, and Pitx3 express both the transgene and the reporter gene eGFP, $4 \mathrm{~d}$ after transduction. Scale bars, $50 \mu \mathrm{m}$

times. We performed immunocytochemistry using standard protocols. Primary antibodies and dilutions were as follows: rabbit anti-aldehyde dehydrogenase 1A (ALDH1A) (1:200; gift from Dr. R. G. Lindahl, University of South Dakota School of Medicine, Vermillion, SD), mouse anti- $\beta$-III-tubulin (1:500, catalog \#T8660; Sigma), rabbit anti- $\beta$-IIItubulin (1:1000, catalog \#PRB-435P; Nordic BioSite, Capistrano Beach, CA), mouse anti-calbindin (1:1000, catalog \#C9848; Sigma), mouse anti$2^{\prime}, 3^{\prime}$-cyclic nucleotide $3^{\prime}$-phosphodiesterase (CNPase) (1:1000, catalog \#C5922, Sigma), rabbit anti-dopamine transported (DAT) (1:400, catalog \#DAT13-A; Alpha Diagnostic, San Antonio, TX), rabbit anti-dopa decarboxylase (1:500, catalog \#AB1569; Millipore Bioscience Research Reagents, Temecula, CA), chicken anti-eGFP (1:1000, catalog \#AB16901; Millipore Bioscience Research Reagents), mouse anti-EN1 (engrailed homolog 1) (1:200, 4G11; Developmental Studies Hybridoma Bank, University of Iowa, Iowa City, IA), mouse anti-Girk2 (G-protein-gated inwardly rectifying $\mathrm{K}^{+}$channel 2) (1:80, catalog \#APC-006; Alomone Labs, Jerusalem, Israel), rabbit anti-glial fibrillary acidic protein (GFAP) (1:1000, catalog \#Z0334; Dako, Carpinteria, CA), mouse anti-Lmxla (1:200, gift from Dr. M. German, University of California, San Francisco, CA), mouse anti-Msx1 (1:200, 4G1; Developmental Studies Hybridoma Bank), mouse anti-microtubule-associated protein 2 (MAP2) (1:500, catalog \#M4403; Sigma), mouse anti-Nestin (1:200, catalog \#556309; BD PharMingen, San Diego, CA), rabbit anti-Ngn2 (1:200, catalog \#AB5682; Millipore Bioscience Research Reagents), rabbit anti-Pitx3 [1:200; gift from Dr. M. P. Smidt, Rudolf Magnus Institute of Neuroscience, University Medical Center Utrecht, Utrecht, The Netherlands; also purchased from Zymed, South San Francisco, CA (catalog \#38-2850)], mouse anti-SOX2 (SRY-box containing gene 2) (1:50, catalog \#MAB2018; R\&D Systems), mouse anti-TH (1:500, catalog \#MAB318; Millipore Bioscience Research Reagents), rabbit anti-TH (1:500, catalog \#AB152; Millipore Bioscience Research Reagents), and rabbit antivesicular monoamine transporter 2 (VMAT2) (1:500, catalog \#AB1767; Millipore Bioscience Research Reagents). Biotinylated antibodies (antimouse and anti-rabbit) were used at the concentration 1:200 and purchased from Vector Laboratories (Burlingame, CA). Fluorochromeconjugated antibodies were used at the concentration of 1:200 and purchased from Invitrogen: Alexa488 goat anti-chicken (catalog \#A11039), Alexa594 goat anti-mouse (catalog \#A11007), Alexa594 goat anti-rabbit (catalog \#A11005), Alexa594 goat anti-rat (catalog \#A11012), and streptavidin Alexa647 (catalog \#S32357). These antibodies were on $30-\mu \mathrm{m}$-thick coronal sections through the substantia nigra of an adult Sprague Dawley rat (supplemental Fig. 2, available at www.jneurosci.org as supplemental material) and had been reported previously (Roybon et al., 2005).

Chloro-deoxyuridine pulse labeling and immunocytochemistry. We cultivated second-passage VM neurospheres generated from E14.5 rat embryos in proliferation medium for $7 \mathrm{~d}$, followed by an overnight transduction with the different viral vectors. We then incubated them from day 13 to day 16 with chloro-deoxyuridine (CldU) (20 $\mu \mathrm{M}$; Sigma), as represented in Figure $4 \mathrm{~A}$. For immunocytochemistry, we fixed the cultures with $4 \%$ paraformaldehyde at day 16 , rinsed with PBS three times, treated with $1 \mathrm{M} \mathrm{HCl}$ at $65^{\circ} \mathrm{C}$ for $10 \mathrm{~min}$, and then incubated with antiCldU/BrdU serum raised in rat (1:200, monoclonal; Immunologicalsdirect, Oxfordshire, UK). The remainder of the procedure followed the protocol for immunocytochemistry mentioned above.

Cell counting and statistical analyses. We quantified neuronal differentiation of rat and human midbrain neural progenitors after transduction, using a fluorescence microscope or after screening using a confocal microscope. We quantified the numbers of stained cells on days 8 and 12 after transduction, with the exception of cleaved caspase 3 and nestin immunostaining that we studied at $4 \mathrm{~d}$ after gene transduction. We examined four fields of view per condition (more than 2000 cells per field) for three independent experiments. To assess the effect of SHH/FGF8 on dopaminergic differentiation and cell-cycle exit, we studied four fields of view in two and three experiments for rat and human cultures, respectively. We randomly selected fields of view and assessed them for the total numbers of eGFP-positive cells and the number of immunopositive cells for each of the markers (marker/eGFP double-immunopositive cells). For double transduction, we performed two independent experiments. We performed statistical comparisons with one- or two-factor ANOVA with time and gene as factors, followed by post hoc analysis when we observed significant differences. We express the data as the mean number 


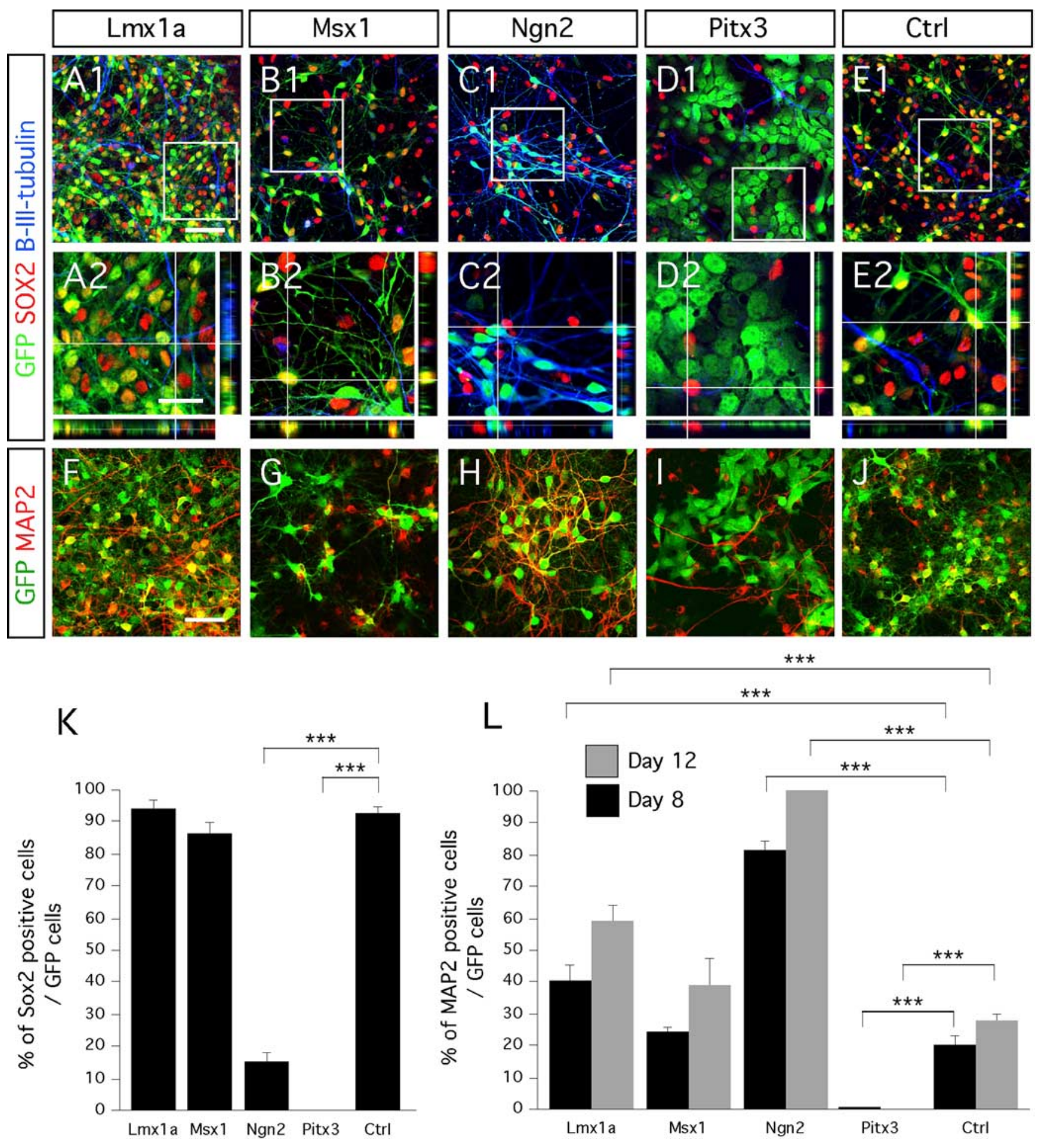

Figure 2. Maturation and neuronal differentiation of E14.5 rat midbrain progenitors after $8 \mathrm{~d}$ in vitro differentiation. A1-D2, In $4 \mathrm{~d}$ differentiated cultures, Lmx1a- and Msx1-transduced cells do not completely downregulate the expression of the immature neural marker S0X2 as opposed to Ngn2-and Pitx3-transduced cells. $\boldsymbol{F}$-J, Transduced progenitors adopt a neuronal morphology and express MAP2 when overexpressing $\operatorname{Lmx1a}(\boldsymbol{F})$ and $\operatorname{Ngn} 2(\boldsymbol{H})$. Neuronal differentiation was not affected when cells were transduced with Msx $1(\boldsymbol{G})$ compared with control $(\boldsymbol{J})$. Cells transduced with Pitx3 do not express MAP2 in combination with the transgene, even after 12 differentiation $(\boldsymbol{I}) . \boldsymbol{K}, \boldsymbol{L}$, Bar diagrams representing the percentage of SOX2-and MAP2-positive cells of the number of transduced GFP-positive cells, after day 8 of in vitro differentiation. High magnification of the framed areas in $\mathbf{A 1}, \mathbf{B 1}, \mathbf{C 1}, \mathbf{D 1}$, and $\mathbf{E 1}$ are represented in $\mathbf{A 2}, \mathbf{B 2}, \mathbf{C 2}, \mathbf{D 2}$, and $\mathbf{E 2}$, respectively. Rectangular images on the bottom and right of $\mathbf{A 2}, \mathbf{B 2}, \mathbf{C 2}, \mathbf{D 2}$, and $\mathbf{E 2}$ represent a projection of $14 \mathrm{Z}$-stack images (total of $10-14 \mu \mathrm{m}$ thick). The crosshairs in $\mathbf{A 2}$ were positioned to show a cell transduced (eGFP), positive for $\beta$-III-tubulin and negative for SOX2. Scale bars: A1, B1, C1, D1, E1, F-J, $50 \mu \mathrm{m} ; A 2, B 2, C 2, D 2, E 2,25 \mu \mathrm{m}$.

of positive cells \pm SEM. Bar diagrams represent the percentage of cells immunopositive for each marker of the number of eGFP-transduced cells. For each diagram, the level of significance ( $p$ value) is represented as follows: ${ }^{*} p<0.05 ;{ }^{* *} p<0.01 ;{ }^{* *} p<0.001$.

Microscopy and images. After immunocytochemistry, we analyzed the specimens using a Leica (Wetzlar, Germany) fluorescence microscope (Leica DMRBE, Openlab software) and Leica confocal microscope (Leica software, equipped with an organ/neon and a helium/neon laser, using the following lines of excitation: 488, 594, and $647 \mathrm{~nm}$ ). We used $20 \times$, $40 \times$, and $63 \times$ objectives. We adjusted images of the positive immuno- 

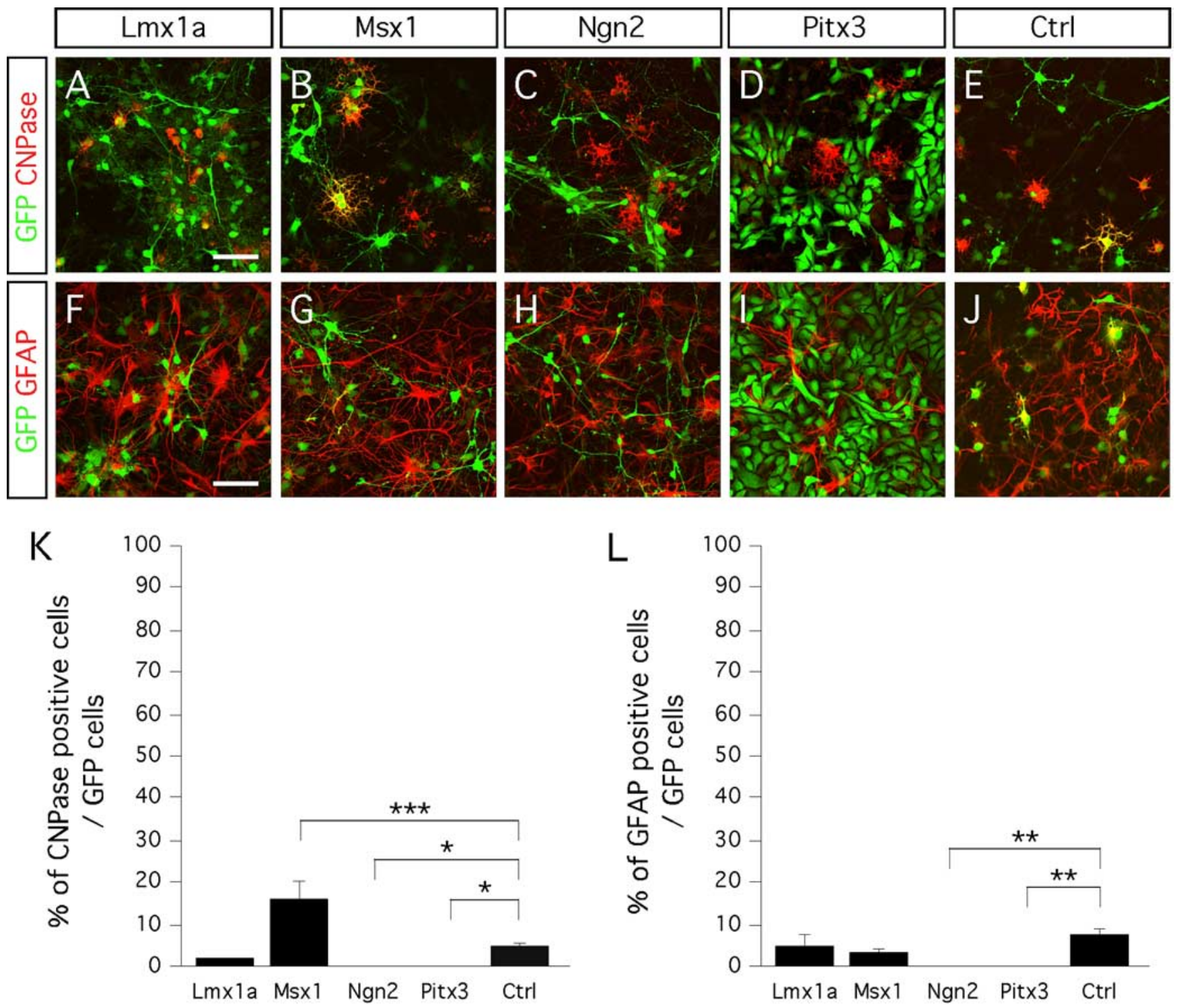

Figure 3. Glial phenotype of cells overexpressing Lmx1a, Msx1, Ngn2, and Pitx3. A-E, Ventral midbrain progenitors express the oligodendrocyte marker CNPase when transduced with Lmx1a $(\boldsymbol{A}), \operatorname{Msx} 1(\boldsymbol{B})$, and control virus $(\boldsymbol{E})$, but never when transduced with either $\operatorname{Ngn} 2(\boldsymbol{C})$ or Pitx3 (D). $\boldsymbol{F}-\boldsymbol{J}$, Ventral midbrain progenitors express the astrocyte marker GFAP when transduced with $L \mathrm{Lm}$ 1a $(\boldsymbol{F}), \operatorname{Msx1}(\boldsymbol{G})$, and control virus $(\boldsymbol{J})$, but not when transduced with either Ngn2 $(\boldsymbol{H})$ or Pitx3 $(\boldsymbol{I}) . \boldsymbol{K}, \boldsymbol{L}$, Bar diagrams representing the percentage of CNPase- and GFAP-positive cells of the number of transduced GFP-positive cells, after day 8 in vitro differentiation. Scale bars, $50 \mu \mathrm{m}$.

histochemical staining to define the optimal use of the dynamic range of detection. We adjusted the background settings to the observed background in positive control specimens (supplemental Fig. 2, available at www.jneurosci.org as supplemental material). We composed figures using CANVAS-X software.

\section{Results}

Effect of Lmx1a, Msx1, Ngn2, and Pitx3 on cell maturation and neuronal differentiation

Knock-out and gene-silencing studies have revealed that Lmx1a, Msx1, Ngn2, and Pitx3 are key transcription factors necessary for the generation and development of dopaminergic neurons (Burbach and Smidt, 2006; Smidt and Burbach, 2007). Retroviruses are suitable tools to deliver foreign genes. They can transduce cultured neural progenitors with higher efficiency (Fig. 1A1-A4) compared with transfection or electroporation techniques (Falk et al., 2002). We studied the phenotype of E14.5 rat midbrain progenitors after retroviral-mediated delivery of each of the transcription factors individually. The transduction efficiency was
$>80 \% 4 \mathrm{~d}$ after transduction, as evaluated by double immunostaining for GFP and the neural progenitor marker Nestin (Fig. 1A1-A4). All transduced cells expressed both the transgene and eGFP, even $12 \mathrm{~d}$ after transduction (Fig. $1 B-E$ ).

We first studied whether the overexpressed genes could prevent maturation, i.e., maintain the neural progenitors in an undifferentiated state. We performed triple immunostaining for eGFP, the neural progenitor marker SOX2 and the immature neuronal marker $\beta$-III-tubulin. We found $\beta$-III-tubulin in all transduced cultures, indicating neuronal maturation (Fig. 2 A1$E 2)$. Downregulation of SOX2 correlated with the appearance of $\beta$-III-tubulin-immunopositive cells in cultures differentiated for 4 d. Statistical analysis confirmed that two genes, Ngn2 and Pitx3, significantly promoted cell maturation (one-factor ANOVA; main effect of the gene, $F_{(4,15)}=479.14 ; p<0.0001$ ) (Fig. $2 K$ ). In cultures transduced with Ngn2, $85.1 \pm 3.4 \%$ of the eGFP-positive cells had downregulated SOX2 expression by $4 \mathrm{~d}$ (Fig. 2C1,C2,K). In cultures transduced with Pitx3, all of the eGFP-positive cells 


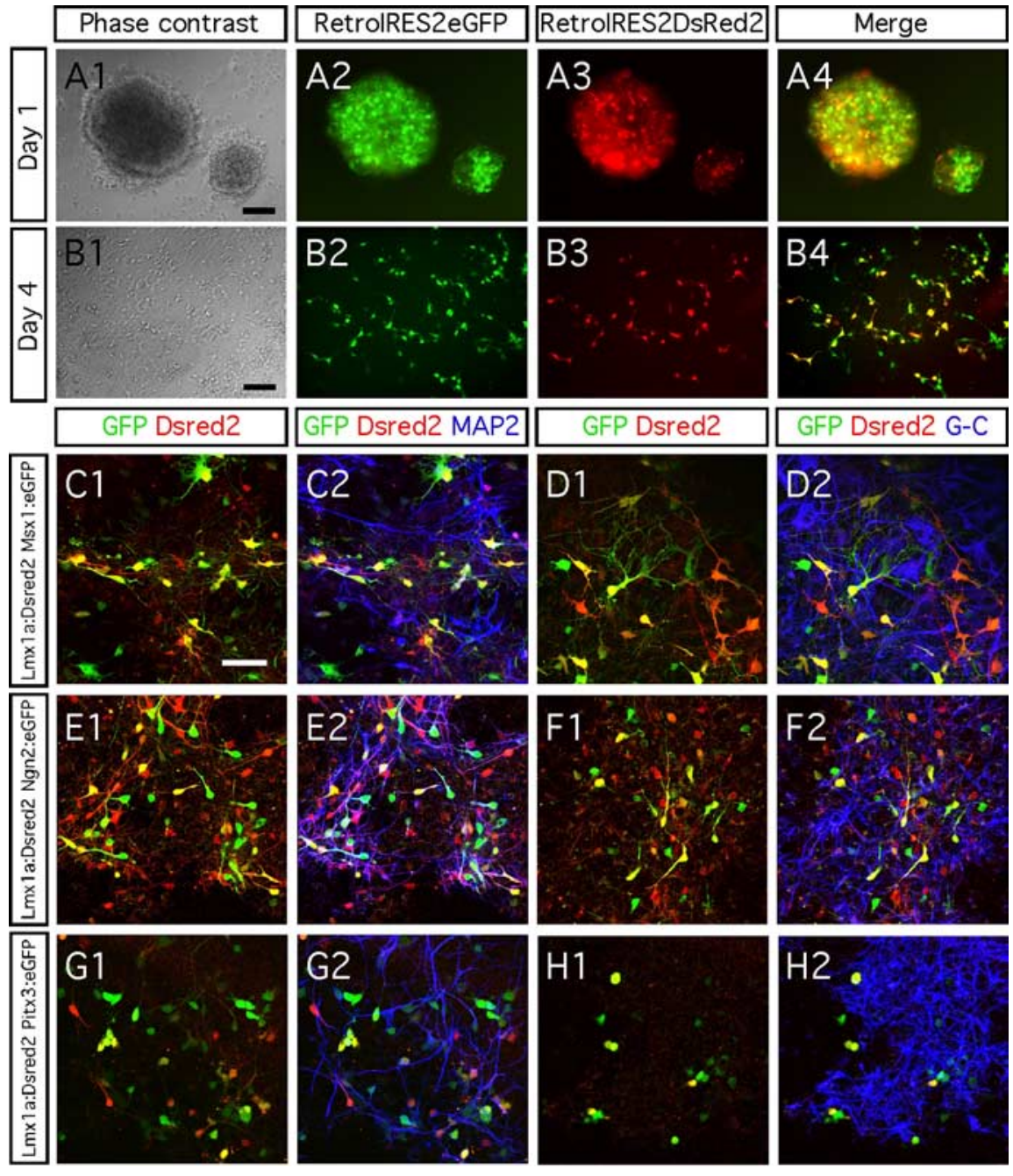

Figure 4. Glial differentiation after dual transgene delivery.A1-B4, Ventral midbrain progenitors grew as neurospheres were double transduced using control retroviruses that drive the expression of DsRed2 or eGFP reporter genes. Using different MOI for each retrovirus (here 0.5 for DsRed control retrovirus and 1 for eGFP control retrovirus) allow us to confirm the specificity of the resulting fluorescence. (1-H2, Ventral midbrain progenitors coexpressing Lmx1a and Ngn2 (E1, E2) become MAP2immunopositive neurons after $8 \mathrm{~d}$ differentiation. Low neuronal differentiation was achieved when overexpressing both $\mathrm{Lm} \times 1 \mathrm{a}$ and Msx1 (C1, (2) or Lmx1a and Pitx3 (G1, G2). Dual transgene delivery had not effect on promoting glial differentiation as shown after a combined immunocytochemistry using the same secondary antibody cyanine 5 to reveal the astrocyte and oligodendrocyte markers GFAP (G-) and CNPase (-C). Scale bars, $50 \mu \mathrm{m}$.

stopped expressing SOX2 (Fig. 2D1,D2,K). Similar results were obtained using the neural progenitor marker Nestin. Less than $5 \%$ of the Pitx3-GFP cells and Ngn2-GFP cells were colabeled with Nestin (supplemental Fig. $1 A, B$, available at www. jneurosci.org as supplemental material).

Because we had observed $\beta$-III-tubulin-expressing cells in transduced cultures, we quantified the increase in cells stained with the mature neuronal marker MAP2 over time (Fig. $2 \mathrm{~F}-J, L$ ). We found a significant increase in the number of MAP2-positive neurons with time (one-factor ANOVA; main effect of time, $F_{(1,20)}=26.09 ; p<0.0001$ ) (Fig. $1 L$ ) and a significant effect of each gene on MAP2 expression compared with control (onefactor ANOVA; main effect of the gene, $F_{(4,20)}=169.55 ; p<$ 0.0001 ) (Fig. $1 L$ ). Both Ngn2 and Lmx1a significantly promoted MAP2 expression. After 8 and $12 \mathrm{~d}$ differentiation, $81.2 \pm 2.6$ and $>99 \%$, respectively, of the eGFP-positive cells were MAP2positive in Ngn2-transduced cultures (Fig. $1 H, L$ ). Lmxla overexpression generated $40.6 \pm 4.3$ and $58.7 \pm 4.9 \%$ MAP2/eGFP- positive neurons in 8 and $12 \mathrm{~d}$ differentiated cultures, respectively (Fig. $1 F, L)$. Interestingly, Pitx3 significantly inhibited neurogenesis (Fig. 1I,L) (onefactor ANOVA; main effect of the gene Pitx3, $\left.F_{(4,20)}=169.55 ; p<0.0001\right)$. Finally, Msxl overexpression had no significant effect on MAP2 expression compare with control (Fig. 1G,L).

Together, our data show that Lmxla and Ngn2 promote neuronal differentiation of neural progenitors.

Effect of Lmx1a, Msx1, Ngn2, and Pitx3 on glial differentiation

Next we examined the capacity of each single gene to induce glial differentiation of E14.5 midbrain neurospheres. We studied the expression of the oligodendrocytic marker CNPase and the astrocytic marker GFAP in cultures differentiated for $8 \mathrm{~d}$ (Fig. 3 ). We observed a significant effect of the genes Msx1, Ngn2, and Pitx3 on oligodendrocyte differentiation (one-factor ANOVA; main effect of the gene, $F_{(4,15)}=$ 20.15; $p<0.001$ ) (Fig. $3 K$ ). The major effect we observed resulted in a fourfold increase in CNPase expression in cultures transduced with Msx1 (Fig. $3 B, K$ ). However, Msxl did not affect differentiation of the progenitors into astrocytes (Fig. 3G,L). Immunocytochemistry for both CNPase and GFAP revealed Ngn2 and Pitx3 significantly inhibited gliogenesis (Fig. $3 C, D, H, I, K, L)$. Transduction with Lmxla did not have any effect on oligodendrogenesis or astrogenesis (Fig. $3 A, F, K, L$ ).

Immunocytochemistry for neuronal, oligodendrocytic, and astrocytic markers showed that some of the overexpressed genes did not drive neuronal or glial differentiation strongly. For example, Pitx3transduced eGFP-positive cells completely downregulated the immature neural progenitor markers SOX2 (Fig. 2D1,D2) and

Nestin (supplemental Fig. $1 B$, available at www.jneurosci.org as supplemental material), but only few became neurons (Fig. $2 I, L$ ) and none of them glia (Fig. $3 D, I, K, L$ ). Their precise phenotype could not be determined, except that they were not neurons or glia and that they exhibited a fibroblast-like morphology.

Together, Msxl promoted oligodendrocyte differentiation of the midbrain neural progenitors, and none of the four genes we studied promoted astroglial differentiation efficiently.

\section{Effect of dual retroviral transgene delivery on neuronal and} glial differentiation

We next studied whether Lmx1a, Msx1, Ngn2, and Pitx3 can synergistically induce neuronal or glial differentiation of ventral midbrain progenitors. Lmxla is the first of the four genes of interest that is expressed during dopamine neuron development. Therefore, in an attempt to promote the generation of midbrainderived neurons, we overexpressed Lmxla combined with each of the three remaining genes. To this aim, we generated a retro- 


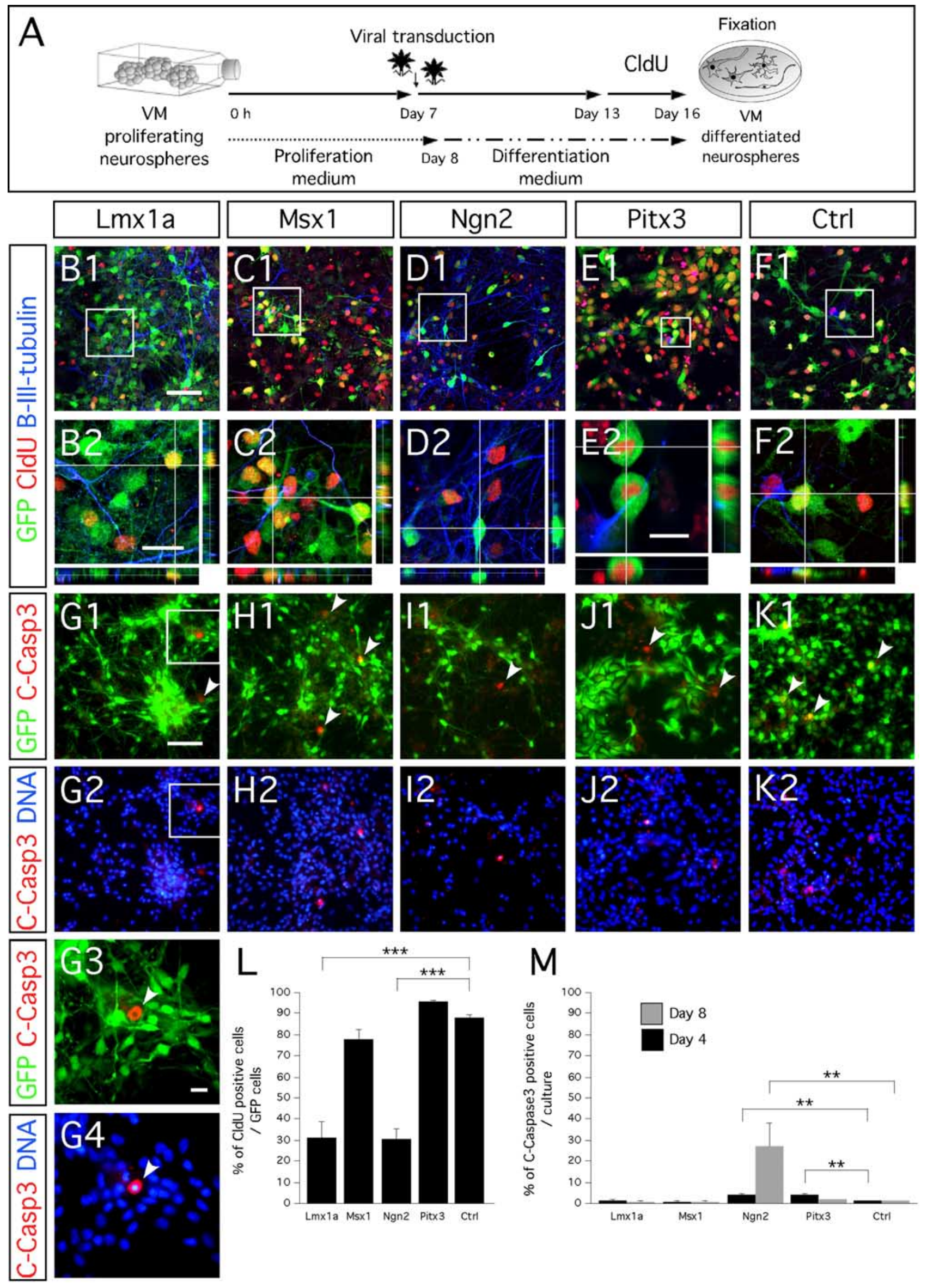


viral vector capable of expressing Discosoma red 2 (DsRed2) reporter gene, in which we subcloned Lmxla. In an initial experiment, we evaluated the efficacy of the dual transgene delivery. For this purpose, we transduced the ventral midbrain progenitors using control retroviruses that only drove the expression of either a DsRed2 or eGFP reporter gene. One day after dual transduction, the cells started to express both reporter genes (Fig. 4A1$A 4$ ), demonstrating that the procedure had worked. At $4 \mathrm{~d}$, a majority of the cells had migrated out of the core neurosphere and expressed both reporter genes. When we used an MOI of 1 , between 30 and $50 \%$ of all cells coexpressed DsRed 2 and eGFP.

We then examined the effects of simultaneously overexpressing two transcription factors. Eight days after dual transgene delivery, $>70 \%$ of Lmxla:DsRed2/Ngn2:eGFP-overexpressing cells were MAP2 immunopositive (Fig. 4E1,E2). This result is similar to that we obtained when we overexpressed Ngn2 alone (Fig. $2 H, L$ ). Thus, isolated Ngn2 overexpression is sufficient enough to promote neuronal differentiation. In contrast, neuronal differentiation was low when we combined Lmxla with Msx1 $(<6 \%)$ or Pitx3 $(<5 \%)$. Indeed, neither dual overexpression of Lmxla and Msx1 nor Lmx1a and Pitx3 increased neuronal differentiation, beyond what we had observed when only overexpressing Msx1 or Pitx3, respectively (Fig. 4C1,C2,G1,G2). When we assessed glial differentiation, we found that almost none of the cells double transduced for the genes of interest expressed GFAP or CNPase (Fig. 4D1,D2,F1,F2,H1,H2).

Together, these data demonstrate that cotransducing ventral mesencephalic progenitors with Lmxla combined with Ngn2, Msx1, or Pitx3 neither enhance neuronal differentiation beyond what is seen when transducing the cells with the transcription factors individually nor promote glial differentiation.

\section{Effect of Lmx1a, Msx1, Ngn2, and Pitx3 on cell-cycle exit, proliferation, and cell death}

To further study the neuronal maturation of the transduced cells, we used CldU incorporation to examine the capacity of each gene to induce cell-cycle withdrawal (Fig. 5). After transduction, we induced the cultures to differentiate for $6 \mathrm{~d}$ and then exposed them to CldU for $72 \mathrm{~h}$. Both Lmx1a- and Ngn2-transduced cells stopped dividing, with $68.5 \pm 7.5$ and $69.1 \pm 4.8 \%$ of transduced GFP-positive cells, respectively, exiting the cell cycle (one-factor ANOVA; main effect of the gene, $F_{(4,15)}=49.45 ; p<0.0001$ ) (Fig. 5B1,B2,D1,D2,L). In contrast, cells overexpressing Msx1 and Pitx 3 continued to proliferate (Fig. $5 C 1, C 2, E 1, E 2, L)$. Interestingly, we observed a much higher frequency of cell mitosis in cultures transduced with Pitx3 (Fig. 5E2). Furthermore, we found that $\sim 90 \%$ of the cells transduced with Pitx3 had incorporated CldU (Fig. 5L).

Finally, we investigated whether each gene influenced cell death at 4 and $8 \mathrm{~d}$ after transduction and differentiation. We immunostained cultures for cleaved caspase3, a marker of ongo- ing apoptosis (Fig. 5G1-G4,H1,H2,I1,I2,J1,J2,K1,K2). We observed an increase in cell death in cultures harboring the Ngn2 and Pitx 3 viruses compared with those infected with Lmxla, Msx1, and control virus in which cell death was $\approx 1.5 \%$ (twofactor ANOVA; effect of the gene, $F_{(4,30)}=10.23 ; p<0.0001$ ) (Fig. 5M) and over time (two-factor ANOVA; effect of time, $F_{(4,30)}=4.76 ; p=0.03$ ) (Fig. 5M). In Ngn2- and Pitx3transduced cultures, $4.5 \pm 0.6$ and $4.1 \pm 0.8 \%$, respectively, of the cells were undergoing apoptosis on day 4 . At $8 \mathrm{~d}$ after transduction, cell death was still low $(<2 \%)$ in cultures transduced with Lmx1a, Msx1, Pitx3, and control virus, but a high level of cell death $(27.3 \pm 10.9 \%)$ could be observed in Ngn2-transduced cultures (Fig. 5M) (supplemental Fig. 1C,D, available at www. jneurosci.org as supplemental material).

\section{Effect of Lmx1a, Msx1, Ngn2, and Pitx3 on dopaminergic differentiation}

In the next step, we studied the dopaminergic phenotype in Lmx1a-, Msx1-, Ngn2-, and Pitx3-transduced cells. TH-positive cells were rare in all culture conditions [fewer than five cells per coverslip, representing less than five cells per $>200,0004^{\prime}, 6^{\prime}$ diamidino-2-phenylindole (DAPI)-positive cells]. Moreover, these TH-positive cells had not been infected with any of the constructs (Fig. 6A1,A2). None of the overexpressed genes significantly induced the expression of the midbrain-related homeobox gene En1 compared with the control-transduced cultures (Fig. 6B1,B2). It was suggested recently that Lmxla, in response to $\mathrm{SHH}$, strongly promotes differentiation of dopaminergic neurons from mouse embryonic stem cells (Andersson et al., 2006b). Therefore, we studied the effect of SHH on Lmxlaand Msx1-transduced rat midbrain cultures. Transduced cells were differentiated with medium supplemented with 1.7 or $15 \mathrm{nM}$ SHH and $100 \mathrm{ng}$ of FGF8, from day 0 to day 16 . We found no increase in the number of TH-immunoreactive transduced cells at days 8,12 , and 16 as a result of the addition of the morphogens to the medium. Together, these data indicate that the single expression of these genes did not promote differentiation of E14.5 rat midbrain neural progenitors into dopaminergic neurons. Furthermore, addition of $\mathrm{SHH}$ at various concentrations and FGF8 did not enhance the dopaminergic differentiation of midbrain cultures transduced with either Lmxla or Msx1 genes.

RT-PCR analysis from cultures transduced with Lmxla, Msx1, Ngn2, and Pitx3 shows that the genes had no effect on enhancing dopaminergic differentiation (Fig. 6C). We detected mRNA for eGFP in all infected cultures. We found an increase in Pitx3 mRNA levels in Pitx3-infected cell cultures on days 4, 8, and 12. We also observed upregulation of the transgene from the other retroviruses carrying Ngn2, Lmxla, and Msx1 (data not shown). We noted that mRNA of Pax2 (paired box gene 2), a key gene of the midbrain identity, was not or very weakly detectable in any of the infected cultures and only weakly expressed in

Figure 5. Ngn2 and Lmx1a but not Msx1 or Pitx3 induce neuronal postmitotic phenotype of ventral mesencephalic progenitors. $\boldsymbol{A}$, Schematic representation of CldU pulse labeling assay. $\boldsymbol{B}$ 1-F2, Cloro-deoxyuridine pulse labeling shows that most of Ngn2-transduced (D1, D2) and Lmx1a-transduced (B1, B2) cells have adopted a postmitotic fate before CIdU exposure and express both the transgene (eGFP) and the neuronal marker $\beta$-III-tubulin. Important cell division was found in Pitx3-transduced cultures as shown by two dividing cells that had incorporated CIdU (E2). Msx1transduced (C1), Pitx3-transduced (E1), and control virus-transduced (F1) cells highly incorporated CldU. High magnification of the framed area in B1, C1, D1, E1, and F1 are represented in B2, C2, $\mathbf{D 2}, \mathbf{E 2}$, and $\boldsymbol{F 2}$, respectively. G1-K2, Immunocytochemistry for cleaved caspase3 (C-Casp3) shows the overexpression of the four genes and control mediated by the retrovirus is not toxic for the cells and does not induce them to undergo apoptosis. G3, G4, High magnification of the framed areas in $\mathbf{G 1}$ and $\mathbf{G 2}$, respectively. G1-K1, White arrowheads show cells immunopositive for cleaved caspase3. G3, G4, White arrowhead shows the phenotypic pyknotic nuclei of a cleaved caspase3-immunopositive cell undergoing apoptosis. $\boldsymbol{L}$, Bar diagram representing the percentage of CIdU-immunopositive cells of the number of transduced GFP-positive cells. $\boldsymbol{M}$, Bar diagram representing the percentage of cleaved caspase3-immunopositive cells of the number of transduced GFP-positive cells after $4 \mathrm{~d}$ (black bars) and $8 \mathrm{~d}$ (gray bars) differentiation. Rectangular images on the bottom and right of B2-F2 represent a projection of 14, 14, 14, 20, and 14 Z-stack images, respectively (total of 10-14 $\mu \mathrm{m}$ thick). Scale bars: B1-F1, G1-K1, G2-K2, 50 $\mu \mathrm{m} ; \mathbf{B 2}-\mathbf{D 2}, \mathbf{F 2}, 20 \mu \mathrm{m} ; \mathbf{E 2}, \mathbf{G 3}, \mathbf{G 4}, 10 \mu \mathrm{m}$. 
freshly dissected E14.5 VM tissue. The loss of the midbrain identity of the expanded ventral mesencephalic progenitors could explain their lack of differentiation into dopaminergic neurons after transgene delivery. We also studied the midbrain dopaminergic subtype identity marker calbindin and found a trend of differentiation toward such phenotype in cultures overexpressing Msx1 (Fig. $6 D-H$ ). In general, the mRNA levels of the cultures transduced with any one of the four transcription factors exhibited only baseline expression profiles for the midbrain dopaminergic markers ALDH1A, DAT, L-amino acid decarboxylase (AADC), and Girk2.

However, RT-PCR data revealed that the VMAT2 mRNA was strongly expressed in the E14.5 VM tissue, whereas it only detected at low levels in all infected cultures at day 4 , except in the cells overexpressing Lmxla and Ngn2 at day 8. Therefore, we decided to further quantify the changes in the number of VMAT2-immunopositive cells generated after transgene delivery. Immunocytochemistry confirmed a highly significant increase in the number of VMAT2/eGFP-positive cells in cultures transduced with Ngn2 virus and over time (two-factor ANOVA; effect of gene $\times$ time, $F_{(4,30)}=4.64 ; p \leq 0.005$ ) (Fig. $\left.6 K, N\right)$. Ngn2 had induced $84.4 \pm 4.8$ and $98.5 \pm$ $1.5 \%$ differentiation into VMAT2-positive cells at days 8 and 12, respectively. In cultures infected with Msx1 or Pitx3, a few cells showed colocalization of eGFP and VMAT2 (Fig. 6J, $L, N$ ). Lmxla had no statistically significant effects on the number of VMAT2-expressing cells (Fig. 6I,N).

Together, these data demonstrate that the genes of interest cannot direct dopaminergic differentiation of ventral mesencephalic progenitors and neither did the combined effect of the genes and the morphogenes SHH and FGF8. However, among the four genes tested, Ngn2 was found to be the most prone to direct the expression of the VMAT2, thus leading to the specific vesicular character of the dopaminergic neuron phenotype.

\section{Dual retroviral transgene delivery fails} to induce dopaminergic differentiation of rat E14.5 midbrain progenitors

During development, different transcription factors synergize to promote neuronal differentiation. Therefore, we simultaneously overexpressed two genes of interest and monitored $\mathrm{TH}$ expression. We transduced cultures with a retrovirus that drives the expression of Lmxla and the reporter gene DsRed2, in combination with another retrovirus that drives the expres-
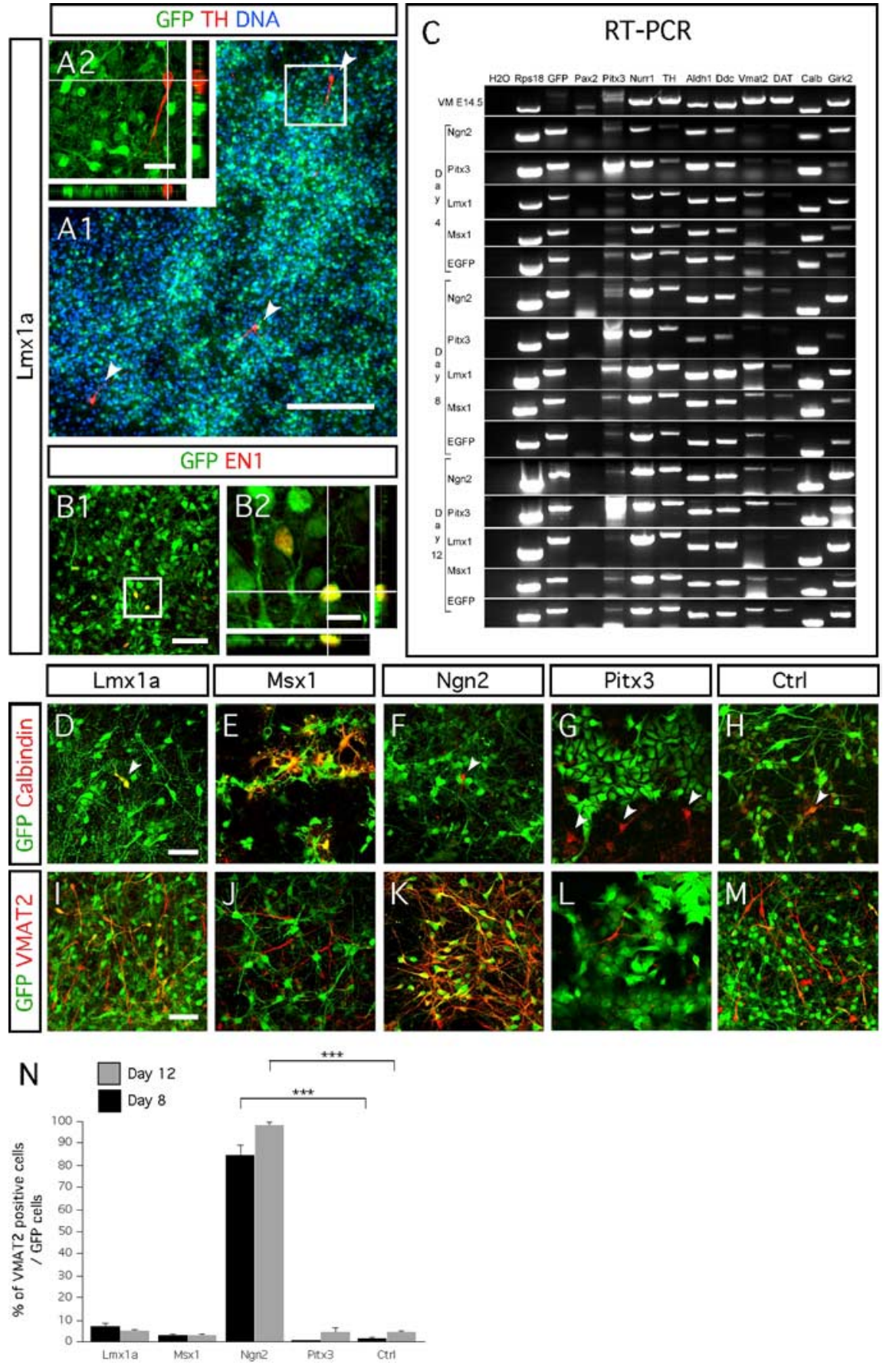

Figure 6. Neural progenitors isolated from E14.5 rat midbrain have a limited capacity to become dopaminergic neurons in response to Lmx1a, Msx1, Ngn2, or Pitx3 overexpression. A1, A2, Cells immunopositive for TH (red) are the result of spontaneous differentiation of nontransduced eGFP-negative progenitors. $\boldsymbol{A} \mathbf{2}$ represents high magnification of the framed area in $\boldsymbol{F}$, showing a TH-immunopositive cell that does not express eGFP. $\boldsymbol{A} \boldsymbol{1}$ is a nonrepresentative picture showing three TH-immunopositive neurons (white arrowheads) among hundreds of Lmx1a transduced eGFP-positive cells. B1, B2, En1 is not induced by Lmx1a overexpression ( $<1 \%$ of the transduced cells express En1). High magnification of the framed area in $\boldsymbol{B} \mathbf{1}$ is represented in $\mathbf{B 2}$. $\boldsymbol{C}$, RT-PCR shows the ventral midbrain progenitors have the capability to differentiate into dopaminergic neurons regardless of Lmx1a, Msx1, Ngn2, or Pitx3 transgene overexpression. $\boldsymbol{D}-\boldsymbol{H}$, Msx1-transduced cells express the midbrain dopaminergic subtype marker calbindin at higher frequency $8 \mathrm{~d}$ after in vitro differentiation than cultures transduced with either $\operatorname{Lmx} 1 \mathrm{a}$, Ngn2, Pitx3, or control retroviruses (although $<1 \%$ of the total number of transduced cells). White arrowhead in $\mathbf{D}-\boldsymbol{H}$ point out single calbindin-immunopositive cells, either transduced or not. $I-M$, VMAT2 expression increases in cultures transduced with Ngn2 $(\boldsymbol{K})$, whereas neither $\operatorname{Msx} 1(\boldsymbol{J})$ nor Pitx3 $(\boldsymbol{L})$ have such an effect, when compared with control cultures transduced with the empty vector $(\boldsymbol{M})$. A trend of increase VMAT2 expression was observed in Lmx1a-transduced cultures $(\boldsymbol{I}, \boldsymbol{N})$. Bar diagrams represent the percentage of VMAT2 ( $\boldsymbol{N}$ )-positive cells of the number of GFP-positive cells, after $8 \mathrm{~d}$ (black bars) and $12 \mathrm{~d}$ (gray bars) of in vitro differentiation. Rectangular images on the bottom and right of $\boldsymbol{A} 2$ represent a projection of 14 stack images on $z$-axis (total of 14 $\mu \mathrm{m}$ thick). Scale bars: $\boldsymbol{A} \mathbf{1}, 200 \mu \mathrm{m} ; \boldsymbol{A 2}, 25 \mu \mathrm{m} ; \boldsymbol{B} \mathbf{1}, \mathbf{D}-\mathbf{M}, 50 \mu \mathrm{m} ; \boldsymbol{B} \mathbf{2}, 10 \mu \mathrm{m}$. 


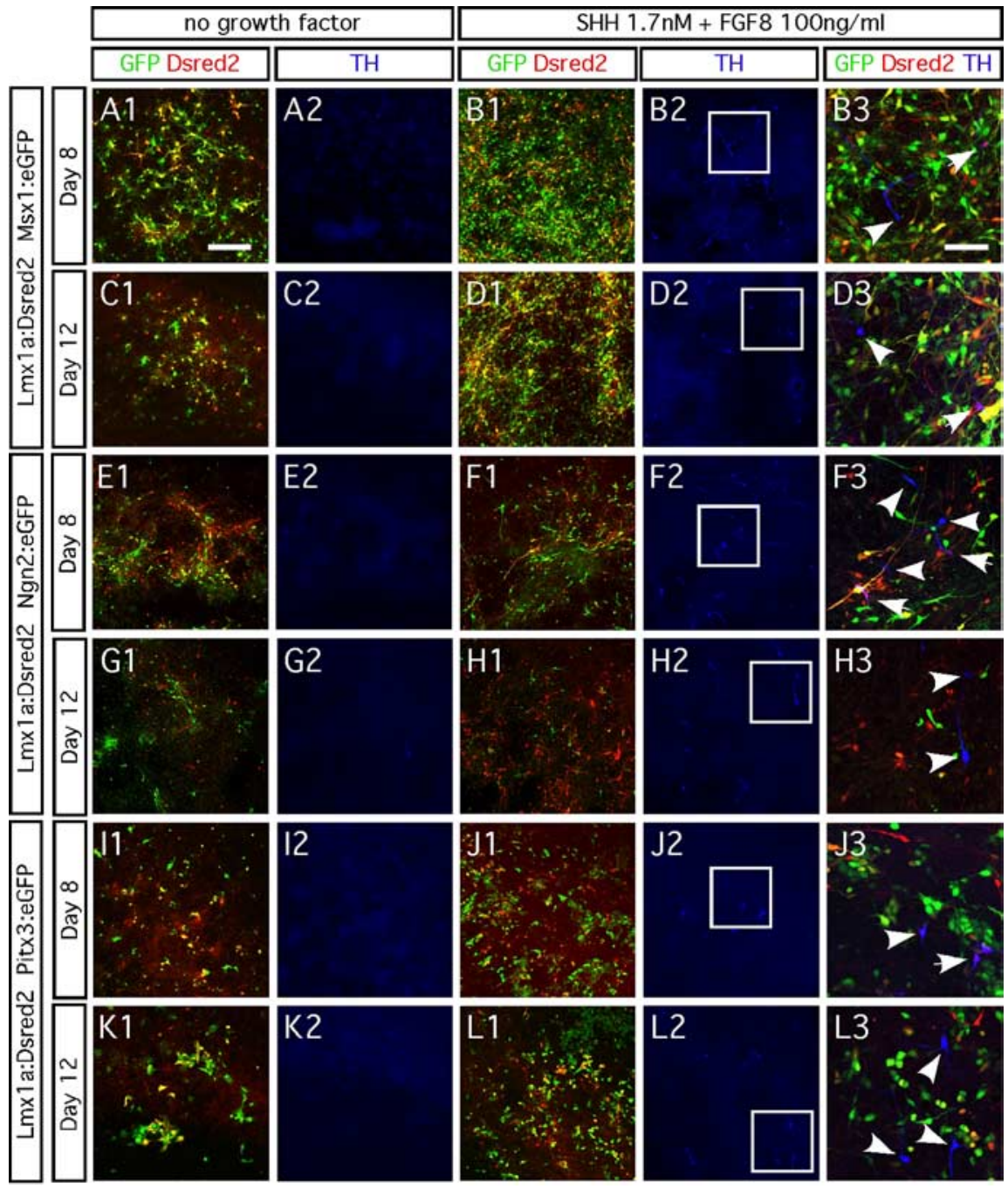

Figure 7. Dual transgene delivery does not promote TH expression. A1-D3, Ventral midbrain progenitors infected with Lmx1a virus labeled with the DsRed2 reporter from an internal ribosome entry site (Lmx1a:DsRed) and Msx1 labeled with eGFP reporter (Msx1:eGFP) do not become TH immunopositive. E1-H3, Ventral midbrain progenitors transduced with Lmx1a:DsRed2 and Ngn2:eGFP do not become TH immunopositive. I1- $\mathbf{3}$, Ventral midbrain progenitors transduced with $L$ mx1a:DsRed2 and Pitx3:eGFP do not become TH immunopositive. Addition of $1.7 \mathrm{~nm} \mathrm{SHH} \mathrm{(data} \mathrm{not} \mathrm{shown)} \mathrm{or} \mathrm{no} \mathrm{growth} \mathrm{factor} \mathrm{did} \mathrm{not} \mathrm{induce} \mathrm{TH}$

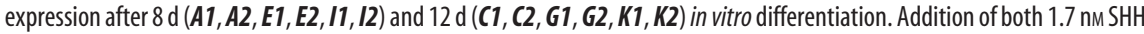
and $100 \mathrm{ng} / \mathrm{ml}$ FGF8 induced TH expression ( $<1 \%$ of the cells), regardless of which transgenes were overexpressed (B1-B3, D1-D3, F1-F3, H1-H3,J1-J3, L1-L3). Right column represents a high-magnification picture of the white frames areas. White arrowheads point at the TH-immunopositive neurons. Scale bar: $\mathbf{A 1}-\mathbf{L 2}, 100 \mu \mathrm{m} ; \mathbf{B} \mathbf{3}-\mathbf{L} \mathbf{3}, 50 \mu \mathrm{m}$.

sion of Msx1, Ngn2, or Pitx3 and the reporter gene eGFP. We subjected them to three conditions: no growth factor, addition of $1.7 \mathrm{~nm} \mathrm{SHH}$, or addition of $1.7 \mathrm{~nm} \mathrm{SHH}$ plus $100 \mathrm{ng} / \mathrm{ml} \mathrm{FGF8.} \mathrm{We}$ did not detect TH expression in any of cells 8 and $12 \mathrm{~d}$ after transduction, regardless of the genes we had overexpressed (Fig. $7 A 1, A 2, C 1, C 2, E 1, E 2, G 1, G 2, I 1, I 2, K 1, K 2)$. When we added SHH, alone or combined with FGF8, some cells expressed TH. However, very few (in Lmx1a/Msx1 and Lmxla/Ngn2 cultures) or almost none (in Lmxla/Pitx3 cultures) of the THimmunopositive cells had been transduced with either of the two genes (Fig. 7B1-B3,D1-D3, F1-F3,H1-H3,J1-J3,L1-L3).

The dual transduction experiment demonstrates that coexpression of Lmx1a and Msx1, Ngn2, or Pitx3 does not promote differentiation of E14.5 rat ventral mesencephalic progenitors into TH-expressing cells, even in the presence of SHH and FGF8.
Retroviral delivery of Lmx1a but not of Msx1 increases dopaminergic differentiation of human midbrain progenitor cell line NGC-407

We also examined whether Lmxla and Msx1 induce differentiation of human immortalized VM-derived progenitors [NGC-407 cell line (Khan et al., 2007)] into dopaminergic neurons. Under basal conditions, proliferating NGC-407 cells are Nestin immunopositive (Fig. $8 \mathrm{~A}$ ) and can differentiate into both $\beta$-III-tubulin-positive neurons (18.1 \pm 4.9\%) (Fig. $8 B$ ) and GFAP-positive astrocytes (22.5 $\pm 4.0 \%)$ (Fig. $8 B$ ). We found a significant threefold increase in the total number of TH-positive cells in NGC-407 cultures transduced with Lmxla (3.2 $\pm 0.5 \%)$ compared with Msx1 $(1.1 \pm 0.1 \%)$ and control $(1.0 \pm 0.1 \%)$ transduced cultures after $6 \mathrm{~d}$ (one-factor ANOVA; $F_{(2,6)}=16.39 ; p<0.05$ ) (Fig. $5 C$ $N)$. Interestingly, the $\mathrm{TH}$-immunopositive cells tended to form clusters (Fig. 8D-F). However, $>95 \%$ of the cells transduced with Lmxla retrovirus (marked with GFP) did not express TH.

These data show that Lmxla can enhance dopaminergic differentiation in human ventral mesencephalic progenitors. Although the threefold increase in the number of TH-expressing neurons is statistically significant, the effect was not apparent in all of the transduced cells.

\section{Discussion}

We investigated the effects of retroviralmediated overexpression of the transcription factors Lmx1a, Msx1, Pitx3, and Ngn2 in rat and human neural progenitors. Under some conditions, neuronal and oligodendrocytic differentiation was promoted. Gain-of-function experiments and knockout studies have demonstrated previously that the four transcription factors are required and essential for proper development and survival of midbrain dopaminergic neurons (Smidt et al., 2004; Andersson et al., 2006b; Kele et al., 2006). Our data show that overexpression of any of these transcription factors, either alone or in dual combinations, was insufficient to induce differentiation of E14.5 rodent ventral midbrain progenitors into dopaminergic neurons. In an immortalized human mesencephalic cell line, we observed a significant, but small, effect of Lmxla overexpression.

Ngn2 induces cell-cycle exit and induces VMAT2 expression Ngn2 is involved in the generation of midbrain dopaminergic neurons. It is expressed close to the midbrain ventricular zone in a population of cells destined to become dopaminergic neurons. In mutant mice, a lack of Ngn2 dramatically reduces the number of dopaminergic neurons (Andersson et al., 2006a; Kele et al., 2006). When Ngn2-expressing cells are harvested from dissociated embryonic ventral mesencephalon of Ngn2-GFP mice using 
fluorescence-activated cell sorting, they preferentially generate dopaminergic neurons, both in culture and after intracerebral transplantation (Thompson et al., 2006). We examined the effects of Ngn2 overexpression in neurospheres generated from E14.5 rat midbrain tissue. The transgene did not lead to the formation of dopaminergic neurons. Instead, Ngn2 induced cell-cycle withdrawal and neuronal differentiation, in keeping with the previously established proneural function of the gene (Nieto et al., 2001). The vast majority of cells transduced with Ngn2 rapidly became postmitotic neurons that expressed VMAT2. Nurr1 knock-out mice exhibit a complete loss of VMAT2 in the VM (Smits et al., 2003), suggesting that Nurr1 expression is obligatory for VMAT2 expression. With this background, it was unexpected that we could not detect Nurr1 expressed with VMAT2 in Ngn2-transduced cultures. Our data demonstrate that, under these conditions, VMAT2 expression is not directly dependent on Nurr1 but can be controlled by Ngn2 in a parallel genetic pathway.

Pitx 3 is involved in the maintenance of the dopaminergic phenotype

Pitx3 plays a role during late stages of the embryonic development of midbrain dopaminergic neurons (Smidt et al., 2004; Zhao et al., 2004). Pitx3 expression commences when AADC-positive dopaminergic neuroblasts have migrated to the ventral part of the central midbrain. This is independent from the Nurrl-mediated transcriptional cascade, because Nurr1 knock-out mice still express Pitx3 and AADC (Smits et al., 2003). The primary role of Pitx3 in the midbrain is to promote the survival of dopaminergic neurons, once they have formed and migrated ventrally. We show that Pitx3-transduced cells stopped expressing Sox 2 and Nestin but did not adopt a neuronal or glial morphology. Interestingly, despite downregulating these markers for immature proliferating neural cells, Pitx3-transduced progenitors continued to divide. During normal development of midbrain dopaminergic neurons, Pitx3 appears after the dopaminergic neuroblasts have become postmitotic. Thus, effects of Pitx3 overexpression on dividing midbrain cells cannot be predicted from normal midbrain development. Indeed, Pitx3, which is normally expressed in different tissues, might play diverse roles depending on when in the cell cycle it is expressed.

In the ventral midbrain, Ngn2 is probably the most potent inducer of cell cycle exit and is expressed before Pitx3 in dopaminergic neurons. In our experiments, we overexpressed Pitx 3 in cells that had not yet expressed Ngn2. Therefore, the action of Pitx3 in our paradigm differed from that seen in normal developing midbrain. Thus, Pitx3 downregulated proteins expressed in immature cells (Sox2 and Nestin), without inducing cell-cycle exit and maturation into neurons or astrocytes. Consequently, our Pitx3-transduced cells could not differentiate into dopaminergic neurons. This is consistent with a recent study showing that mouse and human ESCs overexpressing Pitx3 do not generate dopaminergic neurons (Martinat et al., 2006). Conversely, in mouse ESCs, Pitx3 can maintain already induced TH and DAT expression (Smits et al., 2003).

A previous study showed that signals present in earlier stages of midbrain development are crucial for E14 midbrainderived neurospheres to develop into dopaminergic neurons, and expression of Pitx3 can support their survival. When Pitx3-transduced E14 midbrain-derived neurospheres were cocultured with E11 midbrain explants, an increased number of $\mathrm{TH}$-expressing neurons appeared in the neurospheres (O'Keeffe et al., 2008). Overexpression of Pitx3 in neurospheres cocultured together with cortical explants did not result in an increase in the number of TH-positive neurons. This demonstrates that midbrain explants have a unique capacity, via secreted or membrane-bound factors, to induce dopami- 
nergic neurons in neurosphere cells. In this experimental paradigm, it appears that Pitx3 primarily maintains the dopaminergic phenotype in cells derived from neurospheres.

\section{Driving dopaminergic neuronal differentiation of ventral mesencephalic progenitors by Lmx1a and Msx1}

Lmxla is expressed in several locations in the developing brain. In the ventral midbrain, it is expressed in a spatiotemporal pattern correlating with the onset of midbrain DA neurogenesis (Andersson et al., 2006b). However, Lmxla is also expressed in many nondopaminergic areas of the brain such as the hippocampus, cerebellum, and dorsal spinal cord (Failli et al., 2002). Interestingly, the Lmxla-Msxl transcriptional cascade also exists in the roof plate of the embryonic spinal cord but does not seem to generate dopaminergic neurons in this region (Chizhikov and Millen, 2004a,b; Liu et al., 2004). Expression of Lmxla under the control of the neural stem cell-specific Nestin enhancer in mouse ESC is sufficient to induce midbrain DA neurons, albeit only in the presence of SHH (Andersson et al., 2006b). When we overexpressed Lmxla in either E14.5 neurospheres derived from rat cortex (data not shown) or midbrain, we did not observe an induction of dopaminergic differentiation, even if the cells were grown in the presence of SHH. A lower proportion of Lmxlatransduced cells incorporated CldU, when exposed to the thymidine analog during $3 \mathrm{~d}$, than in control cultures or cultures transduced with Msx1 or Pitx3. These data suggest that either the length of the cell cycle was extended in the Lmxla-tranduced cells or that the pool of proliferating cells was reduced in size because some of them had become postmitotic. Interestingly, an increased proportion of Lmxla-transduced cells expressed the mature neuronal marker $\beta$-III-tubulin, supporting the idea that transduced cells were induced to differentiate. Conversely, the proportion of Lmxla-transduced cells expressing the markers SOX2 and Nestin was also higher than in control cultures, indicating that many of them retained an immature phenotype. Together, the results indicate that Lmxla is an important regulator of cell-cycle exit and induces a complex response in neural progenitors. They further show that the effects of overexpressing Lmxla on cell proliferation are not readily predictable. Therefore, one should be cautious if considering to overexpress Lmxla in cells intended for intracerebral transplantation, because they may proliferate excessively and generate tumors.

Dual overexpression of Lmx1a and Msx1, Ngn2, or Pitx3 was not sufficient to promote mesencephalic-committed progenitors to differentiate into $\mathrm{TH}$-immunopositive neurons. When $\mathrm{TH}-$ immunopositive neurons were found in cultures supplemented with both $\mathrm{SHH}$ and FGF8, the proportion was very low $(<1 \%)$. This indicates that almost all of the E14.5 progenitors have lost their potential to differentiate into dopaminergic neurons.

Overexpression of Lmxla or Msxl in Nestin-positive human NGC-407 cells revealed that Lmxla can promote the generation of $\mathrm{TH}$-immunopositive neurons, albeit to a limited extent, in immortalized human progenitors. The proportion of TH-immunoreactive neurons increased threefold from 1 to $3 \%$. Although the effect represents a proof of principle that Lmxla can promote differentiation of human progenitors into dopaminergic neurons, the cells that expressed TH represented only a small minority of the cells that were transduced by the Lmxla retrovirus. Indeed, the proportion of THimmunoreactive cells was too low to be of practical importance in a neural transplantation context. Additional studies are needed to examine whether the effect can be boosted in human cells.

Several studies have demonstrated that VM-derived neural progenitor cells exhibit limited capacity to differentiate into sta- ble dopaminergic neurons after having been propagated for even short periods. A recent study compared neural progenitor cells derived from E12.5 VM with those obtained from ESCs (Chung et al., 2006). It described that expanded ESC-derived neural progenitor cells retained their potential to differentiate into proper midbrain DA neurons, whereas VM-derived neural progenitor cells lost this ability after expansion. The effect of Lmxla on the human NGC-407 cells indicates that some cells within the NGC407 population remain responsive to the inductive effects of Lmxla. This idea is supported by our observation that THimmunopositive cells tended to locate in patches within the cultures of Lmxla-transduced NGC-407 cells.

Based on our observations, we speculate that unidentified factors critical for effects mediated by transcription factors such as Lmxla are missing in the rat and human midbrain-derived cell cultures. Although Lmxla expression persists throughout adult life, we cannot rule out that the strong overexpression mediated by the retrovirus is not optimal for the promotion of dopaminergic neuron differentiation. Indeed, the reported successful generation of dopaminergic neurons from mouse ESC using a Nestin-enhancerLmxla construct (Andersson et al. 2006) could suggest that a precise dosage of Lmxla is essential for differentiation of the dopaminergic neurons from immature cells. In addition, potential species differences in molecular pathways between mice, rats, and humans must be considered.

We propose that each transcription factor and morphogen needs to be expressed in a specific order that is tightly temporally regulated for dopaminergic neurons to develop from immature progenitors obtained from neurospheres. Possibly, the neurosphere-derived progenitors are not sufficiently immature and may have passed crucial developmental checkpoints that restrict their plasticity after engineering. We must carefully pinpoint each molecular event underlying the development of dopaminergic neurons from their immature precursors to devise protocols that can efficiently engineer midbrain precursors into dopaminergic neurons. Moreover, our results also show that care must be taken to monitor the proliferative capacity of engineered cells if they are to be used safely for transplantation.

\section{References}

Andersson E, Jensen JB, Parmar M, Guillemot F, Björklund A (2006a) Development of the mesencephalic dopaminergic neuron system is compromised in the absence of neurogenin 2. Development 133:507-516.

Andersson E, Tryggvason U, Deng Q, Friling S, Alekseenko Z, Robert B, Perlmann T, Ericson J (2006b) Identification of intrinsic determinants of midbrain dopamine neurons. Cell 124:393-405.

Andersson EK, Irvin DK, Ahlsio J, Parmar M (2007) Ngn2 and Nurr1 act in synergy to induce midbrain dopaminergic neurons from expanded neural stem and progenitor cells. Exp Cell Res 313:1172-1180.

Barberi T, Klivenyi P, Calingasan NY, Lee H, Kawamata H, Loonam K, Perrier AL, Bruses J, Rubio ME, Topf N, Tabar V, Harrison NL, Beal MF, Moore MA, Studer L (2003) Neural subtype specification of fertilization and nuclear transfer embryonic stem cells and application in parkinsonian mice. Nat Biotechnol 21:1200-1207.

Björklund A, Dunnett SB, Brundin P, Stoessl AJ, Freed CR, Breeze RE, Levivier M, Peschanski M, Studer L, Barker R (2003) Neural transplantation for the treatment of Parkinson's disease. Lancet Neurol 2:437-445.

Bryja V, Schulte G, Rawal N, Grahn A, Arenas E (2007) Wnt-5a induces Dishevelled phosphorylation and dopaminergic differentiation via a CK1-dependent mechanism. J Cell Sci 120:586-595.

Burbach JP, Smidt MP (2006) Molecular programming of stem cells into mesodiencephalic dopaminergic neurons. Trends Neurosci 29:601-603.

Castelo-Branco G, Wagner J, Rodriguez FJ, Kele J, Sousa K, Rawal N, Pasolli HA, Fuchs E, Kitajewski J, Arenas E (2003) Differential regulation of midbrain dopaminergic neuron development by Wnt-1, Wnt-3a, and Wnt-5a. Proc Natl Acad Sci USA 100:12747-12752. 
Chizhikov VV, Millen KJ (2004a) Control of roof plate development and signaling by Lmxlb in the caudal vertebrate CNS. J Neurosci 24:5694-5703.

Chizhikov VV, Millen KJ (2004b) Control of roof plate formation by Lmxla in the developing spinal cord. Development 131:2693-2705.

Chung S, Shin BS, Hwang M, Lardaro T, Kang UJ, Isacson O, Kim KS (2006) Neural precursors derived from embryonic stem cells, but not those from fetal ventral mesencephalon, maintain the potential to differentiate into dopaminergic neurons after expansion in vitro. Stem Cells 24:1583-1593.

Failli V, Bachy I, Retaux S (2002) Expression of the LIM-homeodomain gene Lmxla (dreher) during development of the mouse nervous system. Mech Dev 118:225-228.

Falk A, Holmstrom N, Carlen M, Cassidy R, Lundberg C, Frisen J (2002) Gene delivery to adult neural stem cells. Exp Cell Res 279:34-39.

Hofstetter CP, Holmstrom NA, Lilja JA, Schweinhardt P, Hao J, Spenger C, Wiesenfeld-Hallin Z, Kurpad SN, Frisen J, Olson L (2005) Allodynia limits the usefulness of intraspinal neural stem cell grafts; directed differentiation improves outcome. Nat Neurosci 8:346-353.

Jensen JB, Parmar M (2006) Strengths and limitations of the neurosphere culture system. Mol Neurobiol 34:153-161.

Kawasaki H, Mizuseki K, Nishikawa S, Kaneko S, Kuwana Y, Nakanishi S, Nishikawa SI, Sasai Y (2000) Induction of midbrain dopaminergic neurons from ES cells by stromal cell-derived inducing activity. Neuron 28:31-40.

Kawasaki H, Suemori H, Mizuseki K, Watanabe K, Urano F, Ichinose H, Haruta M, Takahashi M, Yoshikawa K, Nishikawa S, Nakatsuji N, Sasai Y (2002) Generation of dopaminergic neurons and pigmented epithelia from primate ES cells by stromal cell-derived inducing activity. Proc Natl Acad Sci USA 99:1580-1585.

Kele J, Simplicio N, Ferri AL, Mira H, Guillemot F, Arenas E, Ang SL (2006) Neurogenin 2 is required for the development of ventral midbrain dopaminergic neurons. Development 133:495-505.

Khan Z, Akhtar M, Asklund T, Juliusson B, Almqvist PM, Ekstrom TJ (2007) HDAC inhibition amplifies gap junction communication in neural progenitors: potential for cell-mediated enzyme prodrug therapy. Exp Cell Res 313:2958-2967.

Kim HJ, Sugimori M, Nakafuku M, Svendsen CN (2007) Control of neurogenesis and tyrosine hydroxylase expression in neural progenitor cells through bHLH proteins and Nurr1. Exp Neurol 203:394-405.

Kim HT, Kim IS, Lee IS, Lee JP, Snyder EY, Park KI (2006) Human neurospheres derived from the fetal central nervous system are regionally and temporally specified but are not committed. Exp Neurol 199:222-235.

Kim JY, Koh HC, Lee JY, Chang MY, Kim YC, Chung HY, Son H, Lee YS, Studer L, McKay R, Lee SH (2003) Dopaminergic neuronal differentiation from rat embryonic neural precursors by Nurr1 overexpression. J Neurochem 85:1443-1454.

Kordower JH, Emborg ME, Bloch J, Ma SY, Chu Y, Leventhal L, McBride J, Chen EY, Palfi S, Roitberg BZ, Brown WD, Holden JE, Pyzalski R, Taylor MD, Carvey P, Ling Z, Trono D, Hantraye P, Deglon N, Aebischer P (2000) Neurodegeneration prevented by lentiviral vector delivery of GDNF in primate models of Parkinson's disease. Science 290:767-773.

Lindvall O, Hagell P (2000) Clinical observations after neural transplantation in Parkinson's disease. Prog Brain Res 127:299-320.

Liu Y, Helms AW, Johnson JE (2004) Distinct activities of Msx1 and Msx3 in dorsal neural tube development. Development 131:1017-1028.

Lothian C, Prakash N, Lendahl U, Wahlstrom GM (1999) Identification of both general and region-specific embryonic CNS enhancer elements in the nestin promoter. Exp Cell Res 248:509-519.

Martinat C, Bacci JJ, Leete T, Kim J, Vanti WB, Newman AH, Cha JH, Gether U, Wang H, Abeliovich A (2006) Cooperative transcription activation by Nurr1 and Pitx 3 induces embryonic stem cell maturation to the midbrain dopamine neuron phenotype. Proc Natl Acad Sci USA 103:2874-2879.

Nieto M, Schuurmans C, Britz O, Guillemot F (2001) Neural bHLH genes control the neuronal versus glial fate decision in cortical progenitors. Neuron 29:401-413.

O'Keeffe FE, Scott SA, Tyers P, O'Keeffe GW, Dalley JW, Zufferey R, Caldwell MA (2008) Induction of A9 dopaminergic neurons from neural stem cells improves motor function in an animal model of Parkinson's disease. Brain 2008 131:630-641.

Olanow CW, Kordower JH, Freeman TB (1996) Fetal nigral transplantation as a therapy for Parkinson's disease. Trends Neurosci 19:102-109.

Ory DS, Neugeboren BA, Mulligan RC (1996) A stable human-derived packaging cell line for production of high titer retrovirus/vesicular stomatitis virus G pseudotypes. Proc Natl Acad Sci USA 93:11400-11406.

Perlmann T, Wallen-Mackenzie A (2004) Nurr1, an orphan nuclear receptor with essential functions in developing dopamine cells. Cell Tissue Res 318:45-52.

Perrier AL, Tabar V, Barberi T, Rubio ME, Bruses J, Topf N, Harrison NL, Studer L (2004) Derivation of midbrain dopamine neurons from human embryonic stem cells. Proc Natl Acad Sci USA 101:12543-12548.

Raymon HK, Thode S, Gage FH (1997) Application of ex vivo gene therapy in the treatment of Parkinson's disease. Exp Neurol 144:82-91.

Reynolds BA, Weiss S (1996) Clonal and population analyses demonstrate that an EGF-responsive mammalian embryonic CNS precursor is a stem cell. Dev Biol 175:1-13.

Roybon L, Christophersen NS, Brundin P, Li JY (2004) Stem cell therapy for Parkinson's disease: where do we stand? Cell Tissue Res 318:261-273.

Roybon L, Brundin P, Li JY (2005) Stromal cell-derived inducing activity does not promote dopaminergic differentiation, but enhances differentiation and proliferation of neural stem cell-derived astrocytes. Exp Neurol 196:373-380

Sanchez-Pernaute R, Studer L, Bankiewicz KS, Major EO, McKay RD (2001) In vitro generation and transplantation of precursor-derived human dopamine neurons. J Neurosci Res 65:284-288.

Schulte G, Bryja V, Rawal N, Castelo-Branco G, Sousa KM, Arenas E (2005) Purified Wnt-5a increases differentiation of midbrain dopaminergic cells and dishevelled phosphorylation. J Neurochem 92:1550-1553.

Sgado P, Alberi L, Gherbassi D, Galasso SL, Ramakers GM, Alavian KN, Smidt MP, Dyck RH, Simon HH (2006) Slow progressive degeneration of nigral dopaminergic neurons in postnatal Engrailed mutant mice. Proc Natl Acad Sci USA 103:15242-15247.

Simon HH, Thuret S, Alberi L (2004) Midbrain dopaminergic neurons: control of their cell fate by the engrailed transcription factors. Cell Tissue Res 318:53-61.

Smidt MP, Burbach JP (2007) How to make a mesodiencephalic dopaminergic neuron. Nat Rev Neurosci 8:21-32.

Smidt MP, Smits SM, Bouwmeester H, Hamers FP, van der Linden AJ, Hellemons AJ, Graw J, Burbach JP (2004) Early developmental failure of substantia nigra dopamine neurons in mice lacking the homeodomain gene Pitx3. Development 131:1145-1155.

Smits SM, Ponnio T, Conneely OM, Burbach JP, Smidt MP (2003) Involvement of Nurr1 in specifying the neurotransmitter identity of ventral midbrain dopaminergic neurons. Eur J Neurosci 18:1731-1738.

Studer L, Tabar V, McKay RD (1998) Transplantation of expanded mesencephalic precursors leads to recovery in parkinsonian rats. Nat Neurosci 1:290-295.

Svendsen CN, Caldwell MA, Ostenfeld T (1999) Human neural stem cells: isolation, expansion and transplantation. Brain Pathol 9:499-513.

Thompson LH, Andersson E, Jensen JB, Barraud P, Guillemot F, Parmar M, Björklund A (2006) Neurogenin2 identifies a transplantable dopamine neuron precursor in the developing ventral mesencephalon. Exp Neurol 198:183-198.

Wagner J, Akerud P, Castro DS, Holm PC, Canals JM, Snyder EY, Perlmann $\mathrm{T}$, Arenas E (1999) Induction of a midbrain dopaminergic phenotype in Nurr1-overexpressing neural stem cells by type 1 astrocytes. Nat Biotechnol 17:653-659.

Ye W, Shimamura K, Rubenstein JL, Hynes MA, Rosenthal A (1998) FGF and Shh signals control dopaminergic and serotonergic cell fate in the anterior neural plate. Cell 93:755-766.

Zhao S, Maxwell S, Jimenez-Beristain A, Vives J, Kuehner E, Zhao J, O’Brien C, de Felipe C, Semina E, Li M (2004) Generation of embryonic stem cells and transgenic mice expressing green fluorescence protein in midbrain dopaminergic neurons. Eur J Neurosci 19:1133-1140. 